\title{
Functional Comparisons of Three Glutamate Transporter Subtypes Cloned from Human Motor Cortex
}

\author{
Jeffrey L. Arriza, Wendy A. Fairman, Jacques I. Wadiche, Geoffrey H. Murdoch, Michael P. Kavanaugh, and \\ Susan G. Amara \\ The Vollum Institute for Advanced Biomedical Research, Oregon Health Sciences University, Portland, Oregon 97201
}

Reuptake plays an important role in regulating synaptic and extracellular concentrations of glutamate. Three glutamate transporters expressed in human motor cortex, termed EAAT1, EAAT2, and EAAT3 (for excitatory amino acid transporter), have been characterized by their molecular cloning and functional expression. Each EAAT subtype mRNA was found in all human brain regions analyzed. The most prominent regional variation in message content was in cerebellum where EAAT1 expression predominated. EAAT1 and EAAT3 mRNAs were also expressed in various non-nervous tissues, whereas expression of EAAT2 was largely restricted to brain. The kinetic parameters and pharmacological characteristics of transport mediated by each EAAT subtype were determined in transfected mammalian cells by radiolabel uptake and in microinjected oocytes by voltage-clamp measurements. The affinities of the EAAT subtypes for L-glutamate were similar, with $K_{m}$ determinations varying from 48 to $97 \mu \mathrm{M}$ in the mammalian cell assay and from 18 to $28 \mu \mathrm{M}$ in oocytes. Glutamate uptake inhibitors were used to compare the pharmacologies of the EAAT subtypes. The EAAT2 subtype was distinguishable from the EAAT1/EAAT3 subtypes by the potency of several inhibitors, but most notably by sensitivity to kainic acid (KA) and dihydrokainic acid (DHK). KA and DHK potently inhibited EAAT2 transport, but did not significantly affect transport by EAAT1/EAAT3. Using voltage-clamp measurements, most inhibitors were found to be substrates that ellcited transport currents. In contrast, KA and DHK did not evoke currents and they were found to block EAAT2-mediated transport competitively. This selective interaction with the EAAT2 subtype could be a significant factor in KA neurotoxicity. These studies provide a foundation for understanding the role of glutamate transporters in human excitatory neurotransmission and in neuropathology.

IKey words: glutamate transporter, uptake, amino acids, human, molecular cloning, inhibitor, pharmacology, kainate, neurotoxicity]

Uptake of the acidic amino acids glutamate and aspartate from the extracellular environment is mediated by sodium-dependent transport systems of high affinity that are found in both the

\footnotetext{
Received Feb. 3, 1994; accepted Mar. 15, 1994.

This work was supported by a Hitchings award from the Burroughs Wellcome Fund and National Institutes of Health Grant DA07595 to S.G.A. We thank Yan$\mathrm{Na} \mathrm{Wu}$ for assistance with oocyte expression and electrophysiology, and the Oregon Brain Repository for providing human tissues.

Correspondence should be addressed to Susan G. Amara, Oregon Health Sciences University, The Vollum Institute L-474, 3181 SW Sam Jackson Park Road, Portland. OR 97201-3098.

Copyright (C) 1994 Society for Neuroscience $0270-6474 / 94 / 145559-11 \$ 05.00 / 0$
}

peripheral tissues (Christensen, 1990) and in the nervous system (Kanner and Schuldiner, 1987; Nicholls and Attwell, 1990). Transport serves a special function in the brain by mediating the reuptake of glutamate released at excitatory synapses. Glutamate can be reaccumulated from the synaptic cleft by the presynaptic nerve terminal (Eliasof and Werblin, 1993) or by glial uptake of transmitter diffusing from the cleft (Nicholls and Attwell, 1990; Schwartz and Tachibana, 1990; Barbour et al., 1991). The activities of neuronal and glial transporters influence the temporal and spatial dynamics of the chemical signal in other neurotransmitter systems (Hille, 1992; Bruns et al., 1993; Isaacson et al., 1993), but such effects have not yet been demonstrated at glutamatergic synapses (Hestrin et al., 1990; Sarantis et al., 1993).

Glutamate is a potent neurotoxin and transporter-mediated uptake serves to maintain extracellular glutamate concentrations below toxic levels. Just as the neurotoxic potency of glutamate is diminished by uptake (Choi et al., 1987; Rosenberg et al., 1992), the neurotoxicity of other excitatory amino acids may also be influenced by the nature of their interaction with glutamate transporters The pharmacology of glutamate transporters have been extensively investigated (Balcar and Johnston, 1972; Ferkany and Coyle, 1986; Fletcher and Johnston, 1991; Robinson et al., 1991; Rauen et al., 1992; Robinson et al., 1993), and exhibits a considerable degree of overlap with the pharmacology of glutamate receptors (Chamberlin and Bridges, 1993). Thus, many of the agents that inhibit glutamate uptake are structural analogs of excitatory amino acids that act as glutamate receptor agonists, and whether the compound is a transporter substrate can be an important determinant of its neurotoxicity. The neurotoxic potency of kainic acid (KA), for example, may be enhanced because it is not taken up (Johnston et al., 1979).

Regional differences in the potencies of various glutamate uptake inhibitors have suggested the existence of multiple glutamate transporter subtypes (Ferkany and Coyle, 1986; Fletcher and Johnston, 1991; Robinson et al., 1991; Rauen et al., 1992; Robinson et al., 1993), but a subtype pharmacology has been difficult to establish because of the complex nature of uptake systems in the brain slice, synaptosomes, or other membrane preparations used. An essential step toward understanding the contribution of uptake to the toxicity of excitatory amino acids is the determination of the properties of each transporter subtype.

A gene family that mediates the cellular uptake of acidic and neutral amino acids in mammals has recently been defined by molecular cloning (for reviews, see Amara and Arriza, 1993; Kanner, 1993; Kanai et al., 1993). Three subtypes of high-affinity glutamate transporters were cloned independently (Kanai 
and IIediger, 1992; Pines ct al., 1992; Storck ct al., 1992; Tanaka, 1993), and sequence comparisons revealed extensive regions of amino acid sequence conservation. Particularly striking was the conservation of an amino acid sequence $\mathrm{AA}(\mathrm{I} /$ V)FIAQ found in the mammalian glutamate transporters but also in prokaryotic glutamate and dicarboxylate carriers. We have utilized degenerate oligonucleotides based upon this sequence conservation to isolate related transporter cDNAs from human brain. Recently, we reported the cloning and functional characterization of a neutral amino acid transport system that is also a member of the glutamate transporter gene family defined by the AA(I/V)FIAQ structural motif (Arriza et al., 1993). This same approach has led to the cloning of three excitatory amino acid transporters, EAAT1, EAAT2, and EAAT3, which are similar to the transporters previously isolated from rat and rabbit. Here, we report the structure, distribution, functional expression, and pharmacology of these human EAAT subtypes.

\section{Materials and Methods}

cDNA cloning, sequence analyses, and plasmid constructions. A synthetic oligonucleotide complementary to a portion of GLAST1 (Storck et al., 1992; residues 395-415, ATINMDGTALYEALAAIFIAQ) was synthesized as a hybridization probe. This oligonucleotide sequence $[5$ CTG (A/G)GC (A/G)AT GAA (A/G)AT GGC AGC CAG GGC (C/ T)TC ATA CAG GGC TGT GCC (A/G)TC CAT GTT (A/G)AT GGT (A $\left.G) G C 3^{\prime}\right]$ is 128 -fold degenerate and utilizes human codon preferences. Human motor cortcx RNA was isolated by the method of Chomczynski and Sacchi (1987) and polyA ${ }^{+}$enriched by oligo(dT)-cellulose chromatography. Mixed oligo(dT)-primed and random-primed cDNA was synthesized from this RNA using the Superscript Choice System (Bethesda Research Labs, Gaithersburg, MD) and ligated into גZAPII (Stratagene, La Jolla, CA) to obtain a human cortex cDNA library (termed $\lambda Z A P-h M C$ ) with a complexity of $1 \times 106$ independent clones and an average insert size of $\sim 2$ kilobases $(\mathrm{kb}) . \lambda Z A P-h M C$ was screened with ${ }^{32} \mathrm{P}$-labeled oligonucleotide using the following conditions for hybridization and wash: $1 \times 10^{6} \mathrm{cpm} / \mathrm{ml}$ in $0.5 \mathrm{M} \mathrm{Na}_{2} \mathrm{HPO}_{4}, \mathrm{pH} 7.15$, $7 \%$ SDS for hybridization at $50^{\circ} \mathrm{C}$, and wash at $60^{\circ} \mathrm{C}$ in $2 \times$ SSPE $(20 \times$ SSPE $=3 \mathrm{M} \mathrm{NaCl}, 0.2 \mathrm{M} \mathrm{NaH}_{2} \mathrm{PO}_{4}, 0.02 \mathrm{M} \mathrm{Na}_{2}$ EDTA, pH 7.4) and $1 \%$ SDS. Plasmids were obtained from purified plaques by in vivo excision (Stratagene, La Jolla, CA) and sequenced on both strands using doublestranded template, synthetic oligonucleotide primers (Oligos Etc.), ${ }^{35} \mathrm{~S}$ dATP (New England Nuclear-Du Pont, Natick, MA), and Sequenase 2.0 (United States Biochemical Corp., Cleveland, $\mathrm{OH}$ ). Sequence data analysis was performed using MACVECTOR (IBI, New Haven, CT). The plasmids termed pEAAT1, pEAAT2, and pEAAT3 contained cDNA inserts 4.1 kilobase pairs $(\mathrm{kbp}), 2.5 \mathrm{kbp}$, and $3.4 \mathrm{kbp}$, respectively. pEAAT 1 and pEAAT2 contained in-frame termination codons at the $5^{\prime}$ end of their open reading frames and the nucleotide sequences surrounding the first downstream methionine codon conform to consensus translation initiation sites. No in-frame termination codons were found in the 15 nucleotides upstream of the proposed initiator methionine of pEAAT3, but this sequence also conforms to the consensus initiation sequence and is similar to that reported for the rabbit transporter EAAC1 (Kanai and Hediger, 1992).

The coding sequences of each EAAT subtype were isolated from cDNAs by the polymerase chain reaction (PCR). Thirty cycles of denaturation $\left(1 \mathrm{~min}, 94^{\circ} \mathrm{C}\right)$, annealing $\left(1 \mathrm{~min}, 55^{\circ} \mathrm{C}\right)$, and extension $(2 \mathrm{~min}$, $72^{\circ} \mathrm{C}$ ) were performed in $100 \mu$ l reactions that contained oligonucleotide primers at $1 \mu \mathrm{M}$ each, $10 \mathrm{ng}$ of plasmid cDNA template, $300 \mu \mathrm{M}$ each deoxynucleotide, Vent polymerase and reaction buffer (New England Biolabs). Unique flanking restriction sites (Asp718 and Xba 1 for EAAT 1 and EAAT2, Asp718 and BamH1 for EAAT3) were incorporated into the oligonucleotide primers. Primer sequences $\left(5^{\prime}\right.$ to $\left.3^{\prime}\right)$ were CGCG GGTACC AAT ATG ACT AAA AGC AAT G and CGCG TCTAGA CTA CAT CTT GGT TTC ACT G for EAAT1, CGCG GGTACC ACC ATG GCA TCT ACG GAA G and CGCG TCTAGA TTA TTT CTC ACG TTT CCA AG for EAAT2, CGCG GGTACC GCC ATG GGG AAA CCG GCG and CGCG GGATCC CTA GAA CTG TGA GGT CTG for EAAT3. Digestion of the reaction products with the appropriate restriction enzymes allowed each coding sequence to be subcloned into expression plasmids.
The PCR-generated coding sequences were subcloned into the expression plasmid pCMV5 (Andersson et al., 1989) to generate constructs (termed pCMV-EAAT1, etc.) for functional analyses in transfected mammalian COS-7 cells. EAAT subtype coding sequences were also subcloned into pOTV for expression in Xenopus laevis oocytes. pOTV is an oocyte transcription vector utilizing the $\mathrm{T} 7$ polymerase promoter for in vitro transcription of RNA. The coding sequences were inserted between Xenopus $\beta$-globin 5 ' - and 3 '-untranslated regions derived from pSP64T (Krieg and Melton, 1984) to enhance expression lcvels in oocytes. The resulting expression plasmids are termed pOTV-EAAT1, etc.

Northern blot analysis. Human brain region RNAs were prepared (Chomczynski and Sacchi, 1987) from tissue provided by the Oregon Brain Repository. RNAs were size fractionated on denaturing formaldehyde gels and transferred to nylon membrane. The human peripheral tissue Northern blot was obtained from Clontech Laboratories. The coding sequences of EAAT1, EAAT2, and EAAT3 were excised and radiolabeled with $\alpha{ }^{32} \mathrm{P}-\mathrm{dCTP}$ (New England Nuclear) hy the random priming method (Boehringer Mannheim). Filters were hybridized overnight at $42^{\circ} \mathrm{C}$ with $\mathrm{cDNA}$ probe $\left(10^{6} \mathrm{cpm} / \mathrm{ml}\right)$ in $5 \times \mathrm{SSPE}, 50 \%$ formamide, $7.5 \times$ Denhardt's solution, $2 \%$ SDS, and $100 \mathrm{mg} / \mathrm{ml}$ of denatured salmon sperm DNA. Autoradiography was performed after two $30 \mathrm{~min}$ room temperature washes in $2 \times$ SSPE, $1.0 \%$ SDS, and two 20 min washes at $50^{\circ} \mathrm{C}$ in $0.1 \times$ SSPE, $0.1 \%$ SDS.

Cell transfections and transport assays. COS-7 cells were maintained in DMEM with $10 \%$ fetal calf serum at $5 \% \mathrm{CO}_{2}$. Each EAAT subtype was expressed independently by DEAE dextran-mediated transfection of COS-7 cells with the appropriate expression plasmid (for example, pCMV-EAAT 1). Transfection of pCMV-5 was used to control for the level of endogenous uptake of radiolabeled L-glutamate (or D-aspartate) in each experimental condition. Subconfluent COS-7 cells were plated at a density of $\sim 100,000$ cclls per well in 12-well tissue culture plates and transfected the following day with $0.5 \mu \mathrm{g}$ of plasmid DNA per well essentially as described (Lopeta et al., 1984). Two days posttransfection, the cells are washed three times with $0.5 \mathrm{ml}$ of room temperature D-PBS $\left(2.7 \mathrm{~mm} \mathrm{KCl}, 1.2 \mathrm{~mm} \mathrm{KH}_{2} \mathrm{PO}_{4}, 138 \mathrm{~mm} \mathrm{NaCl}, 8.1 \mathrm{~mm} \mathrm{Na} 2 \mathrm{HPO} 4, \mathrm{pH}\right.$ $\sim 7.4$ ) over a period of $10 \mathrm{~min}$ prior to the uptake assays.

Uptake of radiolabeled substrate or substrate plus inhibitor was assessed at room temperature in $0.5 \mathrm{ml}$ of D-PBS. It was determined that with a substrate concentration of $1 \mathrm{mM}$ the uptake rate was linear for at least $20 \mathrm{~min}$. Routinely, assays were terminated after $10 \mathrm{~min}$. To terminate uptake, cells were washed three times with ice cold PBS and solubilized in $0.5 \mathrm{ml}$ of $0.1 \%$ SDS prior to scintillation counting in 5 $\mathrm{ml}$ of ScintiVerse (Fisher Scientific). All assays contained $100 \mathrm{~nm}^{3} \mathrm{H}$ L-glutamate or ${ }^{3} \mathrm{H}$-D-aspartate diluted as necessary with cold substrate Affinity constant $\left(K_{m}\right)$ determinations measured uptake at 12 different substrate concentrations, while inhibitor constant $\left(K_{i}\right)$ measurements contained $1 \mu \mathrm{M}$ glutamate and 12 different inhibitor concentrations. All points were assayed in triplicate. Data was analyzed using KALEIDAGRAPH (Synergy Software, Reading, PA) for a least-squares fit to the Michaelis-Menten equation and an Eadie-Hofstee transformation. Calculated $V_{\max }$ values (in $\mathrm{pmol} / \mathrm{well} / \mathrm{min}$ ) varied in independent experiments from 51 to 513 for EAAT1, 111 to 894 for EAAT2, and 152 to 624 for EAAT3. Inhibition data were fitted to the Michaelis-Menten equation to determine the $100 \%$ of control value and the $\mathrm{IC}_{50}$. Since the $K_{i}$ calculated using the method of Cheng and Prusoff (1973) does not differ significantly from the determined $\mathrm{IC}_{50}$, these values are presented as $K_{i}$ values. All values provided are the mean \pm SEM of at least three determinations.

Pharmacological agents. Dihydrokainate, kainate, DL-threo- $\beta$-hydroxyaspartic acid, L-cysteine sulfinic acid, $N$-methyl-D-aspartate, $\mathbf{L}$-serine- $O$-sulfate, $L$-aspartate- $\beta$-hydroxymate, $\beta$-glutamic acid, $\mathrm{L}$ - $\alpha$-aminoadipic acid, $L$ - and D-glutamate, $L$ - and $D$-aspartic acid, and $L$-cysteine were obtained from Sigma. Quisqualate, trans-(dicarboxyl)-2,4-methanoglutamic acid, cis-(dicarboxyl)-2,4-methanoglutamic acid, $( \pm$ ) $\beta-p$ chlorophenylglutamic acid, and $S$-sulfo-L-cysteine were from Tocris Neuramin (Bristol, UK). L-Trans-pyrrolidine-2,4-dicarboxylic acid and (S) $\beta$-oxalyl- $\alpha, \beta$-diaminopropionic acid were from Research Biochemicals Inc. (Natick, MA). $N$-acetyl-L-aspartyl-L-glutamate was from Bachem Bioscience (Philadelphia, PA). ${ }^{3} \mathrm{H}-\mathrm{L}$-glutamate $(19.2 \mathrm{Ci} / \mathrm{mmol}){ }^{3} \mathrm{H}$ D-aspartate $(21 \mathrm{Ci} / \mathrm{mmol})$, and ${ }^{3} \mathrm{H}$-kainate $(58 \mathrm{Ci} / \mathrm{mmol})$ were obtained from New England Nuclear-Du Pont (Natick, MA).

Expression of EAAT subtypes in oocytes. Synthetic RNA was transcribed in vitro from pOTV-EAAT1, pOTV-EAAT2, or pOTV-EAAT3 as described (Arriza et al., 1993) and injected into defolliculated stage V-VI Xenopus oocytes. Two to seven days following injection, transport 


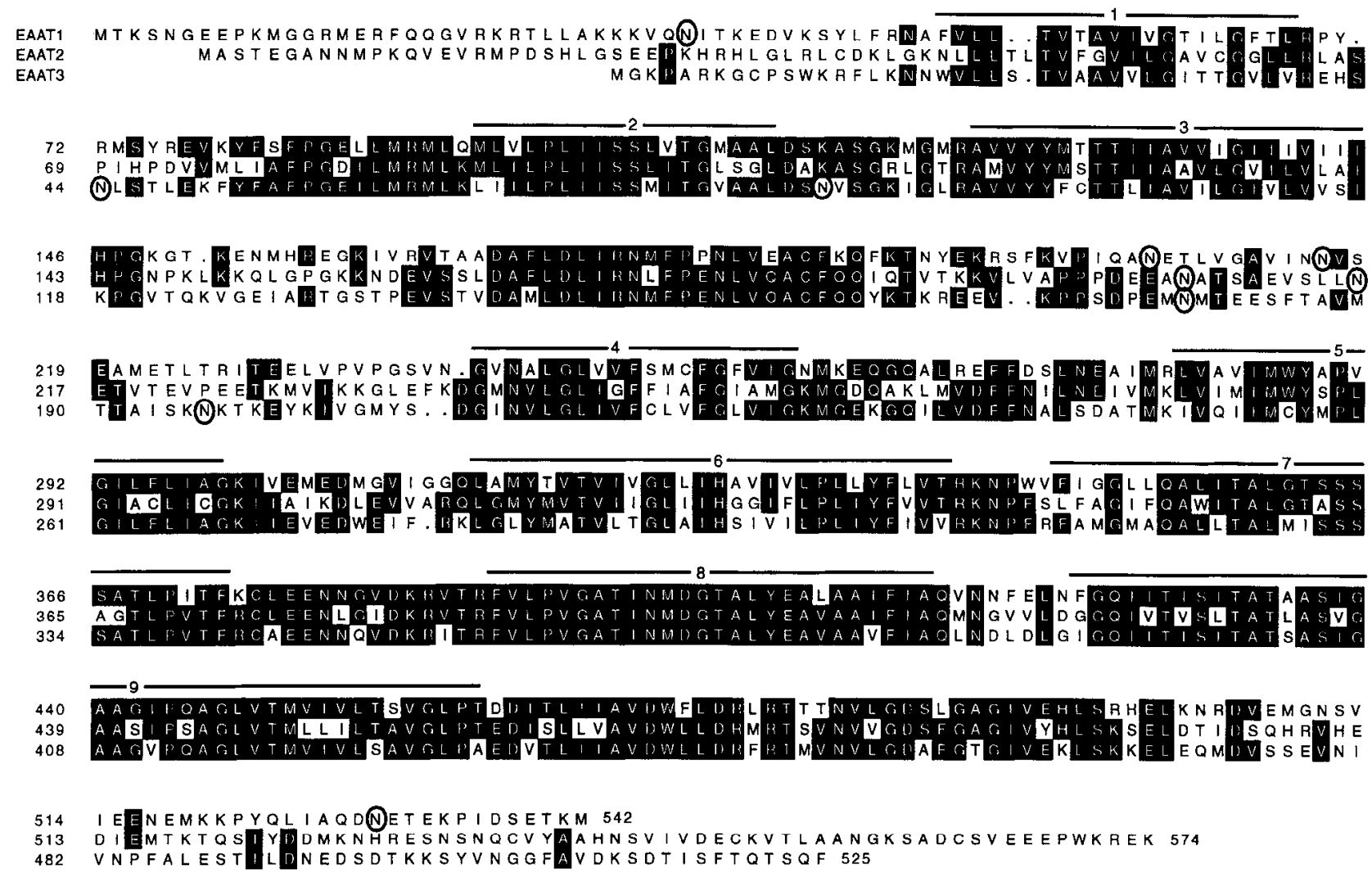

Figure 1. Alignment of the amino acid sequences of the human excitatory amino acid transporters EAAT1, EAAT2, and EAAT3. The amino acid sequences deduced from cDNA nucleotide sequences are depicted. Gaps (dots) have been introduced to facilitate this alignment. Sequence identities are indicated by using white on black lettering at positions where at least two of the three aligned sequences predict identical amino acid residues. Bars are drawn over nine regions of extensive sequence hydrophobicity that may correspond to transmembrane or membrane-associated structures. Potential sites of $\mathrm{N}$-linked glycosylation $(\mathrm{N}-\mathrm{X}-\mathrm{S} / \mathrm{T})$ are indicated by circling the relevant asparagine $(\mathrm{N})$ residues. The nucleotide sequences of EAAT1, EAAT2, and EAAT3 may be obtained from the GenBank database under accession numbers UO3504, UO3505, and UO3506, respectively.

was measured by two-electrode voltage-clamp recording using a Dagan TEV-200 clamp amplifier with an Axon Instruments TL-1 AVD interface. Oocytes were voltage clamped at $-60 \mathrm{mV}$ and continuously superfused with ND-96 buffer ( $96 \mathrm{~mm} \mathrm{NaCl}, 2 \mathrm{mM} \mathrm{KCl}, 1.8 \mathrm{~mm} \mathrm{CaCl}$, $1 \mathrm{~mm} \mathrm{MgCl}$, and $5 \mathrm{~mm}$ HEPES pH 7.5). For transport measurements, this buffer solution was changed to one containing the indicated concentration of substrate. Current $(I)$ as a function of substrate concentration $([S])$ was fitted by least squares to $I=I_{\max } \cdot[S] /\left(K_{m}+[S]\right)$ where $I_{\max }$ is the maximal current and $K_{m}$ is the Michaelis transport constant. Values of $K_{m}$ and $I_{\max }$ are expressed as mean \pm SEM and were determined by fitting data from individual oocytes. The $I_{\max }$ values for transporter substrates are expressed as the $I_{\max }$ relative to that determined for L-glutamate in the same cells. The antagonism of EAAT2 transport by kainic acid and dihydrokainic acid was evaluated using Schild analysis (Arunlakshana and Schild, 1959).

\section{Results}

\section{Molecular cloning of EAAT1, EAAT2, and EAAT3 from} human cortex

The three human glutamate transporters characterized here were isolated as CDNAs from a human motor cortex library using a degenerate oligonucleotide probe (see Materials and Methods). The plasmids pEAAT1, pEAAT2, and pEAAT3 contained distinct cDNA sequences with large open reading frames identified by nucleotide sequence analysis. The predicted amino acid sequences of the encoded proteins, termed EAAT1, EAAT2, and EAAT3, are 542, 574, and 525 amino acids in length, respectively, as shown in Figure 1. The theoretical molecular weights of EAAT1, EAAT2, and EAAT3 are 59.5, 62.1 and 57.2 kDa. On the basis of nucleic acid and amino acid sequence homology, EAAT1, EAAT2, and EAAT3 could correspond to glutamate transporters previously isolated from other species. EAAT1 has $96 \%$ amino acid sequence identity with the rat GLAST1 sequence (Storck et al., 1992). Similarly, EAAT2 has $95 \%$ identity with the corrected sequence (Kanner, 1993) of rat GLT1 (Pines et al., 1992), and EAAT3 has $92 \%$ identity with the rabbit sequence termed EAAC1 (Kanai and Hediger, 1992). However, recent evidence suggests the existence of at least two additional human glutamate transporter subtypes, one of which is strikingly similar to both EAATl and GLAST1 (W. Fairman, unpublished data). Thus it is possible that EAAT1 is a novel subtype rather than the human homolog of GLAST1.

Alignment of the EAAT protein amino acid sequences illustrates the extensive conservation of both primary sequence and other structural features within this gene family. The $\mathrm{N}$ - and C-termini differ in sequence and in length, but $70 \%$ of the positions in the region where these three protein sequences overlap are identical in at least two of the three sequences. Accordingly, the hydropathy profiles of the EAAT subtypes are very similar when algorithms designed to identify transmembrane helices are utilized (Engelman et al., 1986), and nine major regions of amino acid sequence hydrophobicity have been indicated in Figure 1. However, predictions of the secondary structure of these regions are often more consistent with $\beta$-sheets than $\alpha$-hel- 
A

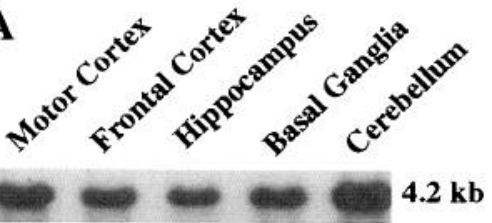

EAAT1

\section{(1)}

EAAT2

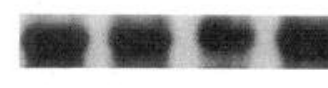

EAAT3

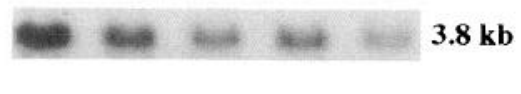

$\beta$-Actin

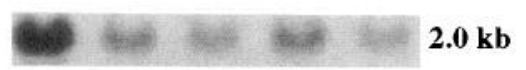

B

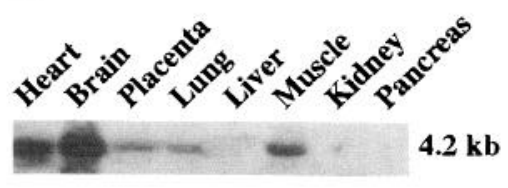

$10.0 \mathrm{~kb}$
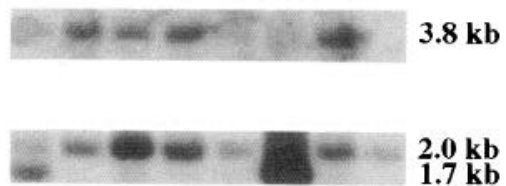

Figure 2. Expression of EAAT subtype mRNAs in human tissues. $A$, Northern blot analyses of RNAs prepared from dissected brain regions with radiolabeled coding sequences for either EAAT1, EAAT2, or EAAT3. Each lane contains approximately $20 \mu \mathrm{g}$ of total RNA, and the autoradiograms were exposed $12 \mathrm{hr}$ for EAAT1 and EAAT2, and $24 \mathrm{hr}$ for EAAT3. The estimated size of each mRNA in kilobases $(k b)$ is indicated. Hybridization of a human $\beta$-actin cDNA probe to a parallel blot suggests that the motor cortex lane contains more RNA than the other lanes. $B$, A single blot containing approximately $2 \mu \mathrm{g}$ of poly $\mathrm{A}^{+}$RNA from each indicated human tissue was successively hybridized with each EAAT cDNA probe. The same filter was also reprobed with a human $\beta$-actin cDNA to normalize for relative mRNA loading. $\beta$-Actin mRNA is approximately 2.0 kb in length, but heart and skeletal muscle contain an abundant $1.7 \mathrm{~kb}$ actin mRNA species that also hybridizes.

ices, and the actual number of transmembrane or membraneassociated domains has not been established. The amino terminus is likely to be intracellular since there is no signal peptide sequence, and the conservation in each subtype of potential $\mathrm{N}$-linked glycosylation sites between the third and fourth hydrophobic regions (Fig. 1) suggests that this domain is extracellular.

\section{RNA distribution by Northern blot analyses}

Northern blot analysis of RNAs prepared from a variety of human tissues was used to determine the distribution of EAAT subtype mRNAs. The subtype mRNA content was compared in five human brain regions (Fig. 2A). Hybridization with an EAAT1 probe revealed a $\sim 4.2 \mathrm{~kb}$ mRNA relatively abundant in all regions examined, but significantly enriched in the cerebellum. In contrast, EAAT2 mRNA $(\sim 10.0 \mathrm{~kb})$ was poorly represented in the cerebellar preparation, but was very abundant in other brain regions. In contrast to the multiple RNA species reported for EAAC1 (Kanai and Hediger, 1992), a single hybridizing band $(\sim 3.8 \mathrm{~kb})$ was seen with the EAAT3 cDNA probe, and this band was found at low levels and in a pattern similar to that observed for the constitutively expressed $\beta$-actin mRNA. Although the rabbit transporter EAAC1 has been reported to exhibit a neuronal pattern of expression (Kanai and Hediger, 1992), EAAT3 mRNA content did not differ significantly between regions such as the hippocampus that have a high density of glutamatergic neurons, and a region like the basal ganglia that has few glutamatergic neurons (Fig. $2 A$ ).

The expression of EAAT subtypes in various human peripheral tissues was also examined (Fig. 2B). EAAT1 RNA was nearly as abundant in heart and skeletal muscle as in brain, and was also detectable in placenta and lung. This result contrasts with the reported brain-specific distribution of the structurally similar rat GLAST1 (Storck et al., 1992). The distribution of EAAT2 mRNA, like GLT1 (Pines et al., 1992), was rather restricted; aside from brain, detectable levels were found in only one other tissue examined, the placenta. EAAT3 RNA was most abundant in kidney with lower levels in brain, lung, and pla- centa, and message detectable in liver, muscle, and heart. The low level of EAAT3 expression in lung and heart also differs somewhat from the reported distribution of EAAC1 (Kanai and Hediger, 1992).

\section{Functional expression in mammalian cells}

Functional characterization of the EAAT subtypes was performed by transient expression in mammalian cells. The coding sequences of each subtype cDNA were inserted into the COS cell expression plasmid pCMV5, and the resulting constructs, pCMV-EAAT1, pCMV-EAAT2, and pCMV-EAAT3, were transfected into COS-7 cells. This expression system provided levels of radiolabeled substrate uptake significantly $(10-100$ fold) greater than that of endogenous COS-7 cell uptake. Endogenous uptake was measured in parallel control experiments in which COS-7 cells were transfected with the parental pCMV5 plasmid, and subtracted from each data point. Each assay point was performed in triplicate and each experiment was performed at least three times.

The kinetics of the cellular uptake of the glutamate transporter substrates L-glutamate and D-aspartate were examined for EAAT1, EAAT2, and EAAT3 (Fig. 3). Uptake (in pmol/well/ $\mathrm{min}$ ) as a function of substrate concentration was fitted by leastsquares to the Michaelis-Menten equation, and the half-maximal transport constant $\left(K_{m}\right)$ was determined using the EadieHofstee transformation (insets, Fig. 3). The $K_{m}$ values of EAAT1, EAAT2, and EAAT3 for uptake of L-glutamate were $48 \pm 10$, $97 \pm 4$, and $62 \pm 8 \mu \mathrm{M}$, respectively (Fig. $3 A, C, E$ ). Uptake of the nonmetabolized amino acid D-aspartate yielded $K_{m}$ values of $60 \pm 12,54 \pm 9$, and $47 \pm 9 \mu \mathrm{M}$ for EAAT1, EAAT2, and EAAT3, respectively (Fig. $3 B, D, F$ ). Subtype $V_{\max }$ determinations could not be directly compared in this assay system because of the dependence on efficiency of transfection and other factors related to the level of expression. The $V_{\max }$ of a single subtype was observed to vary as much as 10 -fold between experiments, and without specific antibodies or high affinity ligands it is not possible to compare the level of expression of a 


\section{A. EAAT1}

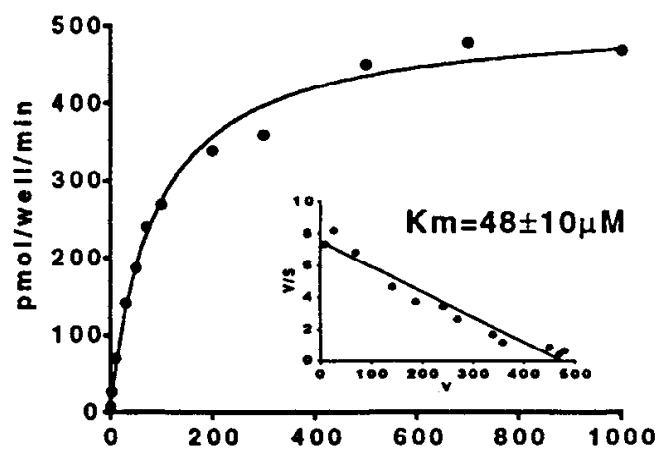

C. EAAT2

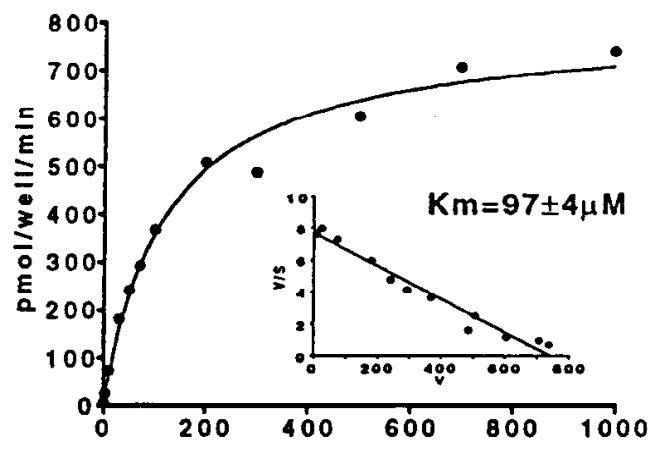

E. EAAT3

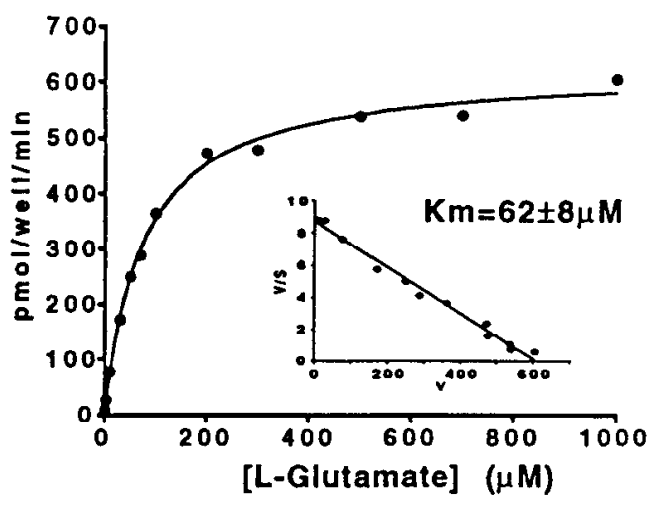

\section{B. EAAT1}

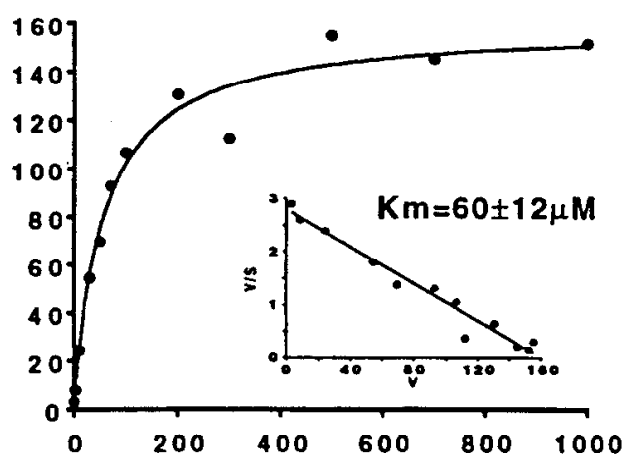

\section{EAAT2}

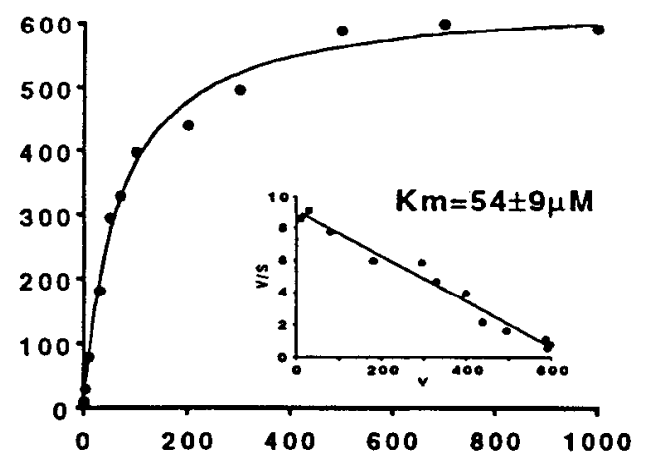

F. EAAT3

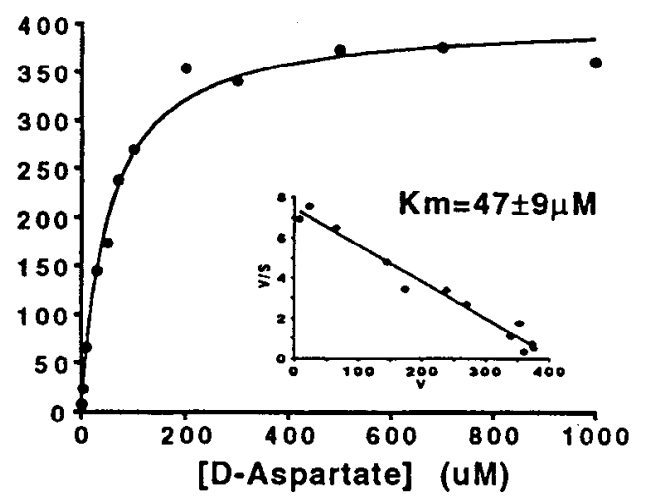

Figure 3. Excitatory amino acid uptake by EAAT subtypes expressed in transfected COS-7 cells. The kinetic properties of the cellular uptake of ${ }^{3} \mathrm{H}$ L-glutamate $(A, C, E)$ or ${ }^{3} \mathrm{H}$-D-aspartate $(B, D, E)$ as mediated by EAAT1 $(A$, $B), \operatorname{EAAT} 2(C, D)$, or EAAT3 $(E, F)$ were assessed by the transient expression of these transporters in COS-7 cells. Uptake velocity (in $\mathrm{pmol} / \mathrm{well} / \mathrm{min}$ ) was measured using $100 \mathrm{nM}$ of radiolabeled amino acid and increasing concentrations of unlabeled amino acid. The data presented are the mean of triplicate determinations from single representative experiments, and individual determinations for each point did not vary from the mean by $>20 \%$. $K_{m}$ values were obtained from the Eadie-Hofstee plots ( $\mathrm{i}$ $s e t s$ ), and the values presented are the mean \pm SEM of at least three independent experiments. particular subtype. There was no evidence, however, that the transport $K_{m}$ was affected by expression level.

\section{Pharmacological characterization of the EAAT subtypes}

The pharmacological properties of the human glutamate transporter subtypes were characterized in assays similar to those described above, but with a fixed concentration of radiolabeled glutamate $(1 \mu \mathrm{M})$ and varying drug concentrations. Candidate drugs were initially tested at three concentrations $(3 \mu \mathrm{M}, 100$ $\mu \mathrm{M}, 3 \mathrm{mM}$ ) to determine their potency and specificity. This threepoint screen was subsequently found to provide approximate $K_{i}$ values generally consistent with those determined by more complete (6-12 point) assays. The following compounds were only characterized by three-point assays. $\mathrm{HgCl}_{2}$ was a potent inhibitor of EAAT1, EAAT2, and EAAT3 $\left(K_{i}=31 \mu \mathrm{M}, 99 \mu \mathrm{M}\right.$, and $62 \mu \mathrm{M}$, respectively; $n=2$ ). Trans-(dicarboxyl)-2,4-methanoglutamic acid, an uptake inhibitor reported to be relatively inactive at glutamate receptors (Fletcher et al., 1991), provided $K_{i}$ estimates of $120 \pm 21,660 \pm 153$, and $244 \pm 94 \mu \mathrm{M}(n=$ 3) for EAAT1, EAAT2, and EAAT3. Its stereoisomer [cis-(dicarboxyl)-2,4-methanoglutamic acid], a NMDA receptor agonist (Lanthorn et al., 1990), did not inhibit uptake. Compounds with determined $K_{i}$ values of $\geq 1 \mathrm{mM}$ in this assay system were defined as inactive. Other inactive compounds were NMDA, quisqualate, $(S)$ - $\beta$-oxalyl- $\alpha, \beta$-diaminopropionic acid (ODAP); $( \pm) \beta$-p-chlorophenylglutamic acid, $N$-acetyl aspartylglutamate (NAAG), L-cysteine, and $S$-sulfo-L-cysteine. L- $\alpha$-Aminoadipate, a classical inhibitor of glutamate uptake in rat (Balcar and Johnston, 1972), was examined as an inhibitor of the EAAT subtype and the measured $K_{i}$ values were $>1 \mathrm{~mm}$. 


\section{A. EAAT1}

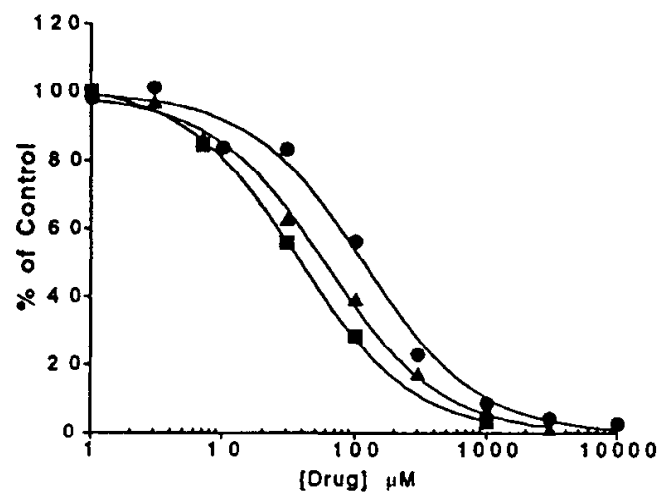

\section{B. EAAT2}

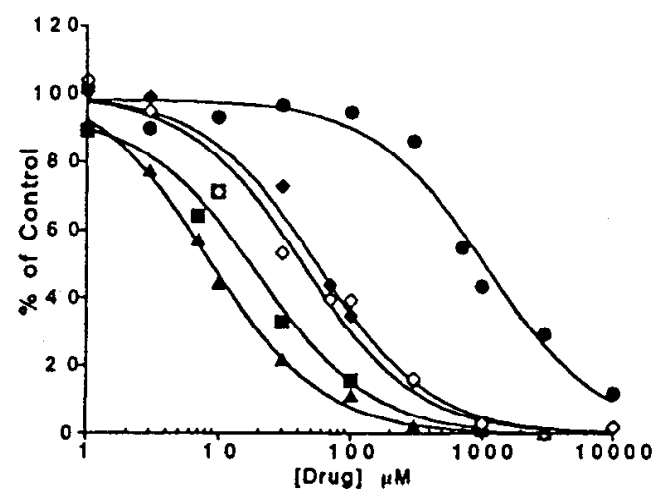

\section{EAAT3}

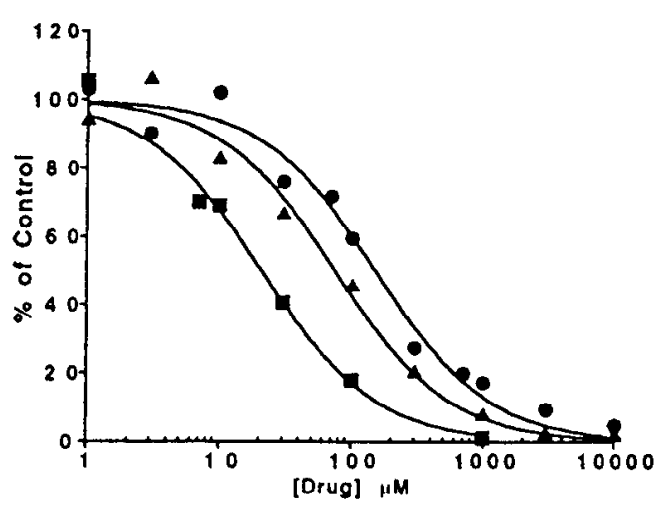

Figure 4. Pharmacology of EAAT subtypes expressed by COS cell transfection. The potencies of glutamate uptake inhibitors were assessed in COS cells transfected with either EAAT1 $(A)$, EAAT2 $(B)$, or EAAT3 $(C)$. Uptake of $1 \mu \mathrm{M}{ }^{3} \mathrm{H}$ L-glutamate was assessed in the presence of the indicated amount of inhibitor. Inhibitors were T $\beta \mathrm{HA}$ (solid squares), PDC (solid triangles), SOS (solid circles), DHK (open diamonds), and $\mathrm{KA}$ (solid diamonds). DHK and KA had no significant effect on EAAT1and EAAT3-mediated uptake at concentrations $\leq 1 \mathrm{mM}$ (data not shown). Each data set shown is from a single representative experiment performed in triplicate with individual determinations varying from the mean by $<20 \%$. The $K_{i}$ values listed in Table 1 are from at least three independent experiments (mean \pm SEM). Chemical names of the compounds abbreviated above are given in Table 1 .

Potentially selective and/or potent inhibitors were more extensively characterized by full $K_{i}$ determinations. Representative data for the effect of five uptake inhibitors (T $\beta H A$, PDC, SOS, DHK, and KA) on transport by each EAAT subtype are presented in Figure 4 , and $K_{i}$ values are provided for these and other inhibitors (CA, LCSA, $\beta$-GLU, and LA $\beta \mathrm{H}$ ) in Table 1.
Table 1. Glutamate uptake inhibition constants

\begin{tabular}{lccc} 
& \multicolumn{3}{l}{$K_{i}$ determined $($ in $\mu \mathbf{M})$} \\
\cline { 2 - 4 } Compound $^{a}$ & EAAT1 & EAAT2 & EAAT3 \\
\hline T $\beta$ HA & $32 \pm 8$ & $19 \pm 6$ & $25 \pm 5$ \\
PDC & $79 \pm 7$ & $8 \pm 2$ & $61 \pm 14$ \\
SOS & $107 \pm 8$ & $1157 \pm 275$ & $150 \pm 52$ \\
DHK & $>3 \mathrm{mM}$ & $23 \pm 6$ & $>3 \mathrm{mM}$ \\
KA & $>3 \mathrm{mM}$ & $59 \pm 18$ & $>3 \mathrm{mM}$ \\
CA & $10 \pm 3$ & $10 \pm 2$ & $19 \pm 9$ \\
LCSA & $14 \pm 7$ & $6 \pm 1$ & $17 \pm 2$ \\
$\beta$-Glu & $297 \pm 118$ & $156 \pm 37$ & $307 \pm 48$ \\
LA $\beta$ H & $369 \pm 70$ & $184 \pm 27$ & $133 \pm 34$
\end{tabular}

${ }^{a} \mathrm{~T} \beta \mathrm{HA}$, DL-threo- $\beta$-hydroxyaspartic acid; PDC, L-trans-pyrrolidine-2,4-dicarboxylic acid; SOS, L-serine- $O$-sulfate; DHK, dihydrokainic acid; KA, kainic acid; CA, L-cysteic acid; LCSA, L-cysteine sulfinic acid; $\beta$-Glu, $\beta$-glutamate; LA $\beta \mathrm{H}$, $L$-aspartate- $\beta$-hydroxymate.

Tablc 1 also lists the abbreviations and full chemical names of these inhibitors. T $\beta \mathrm{HA}$ and PDC were potent inhibitors of each subtype, but PDC was more potent than T $\beta$ HA on EAAT2 while T $\beta$ HA was more potent than PDC on EAAT1 and EAAT3. KA and DHK inhibited EAAT2 uptake with $K_{i}$ values of $59 \pm 18$ $\mu \mathrm{M}$ and $23 \pm 6 \mu \mathrm{M}$, respectively, but had no significant effect on the activity of EAAT1 and EAAT3 at concentrations less than $1 \mathrm{mM}$. In contrast, SOS inhibited EAAT1 and EAAT3 with $K_{i}$ values of $107 \pm 8 \mu \mathrm{M}$ and $150 \pm 52 \mu \mathrm{M}$, but was determined to have a $K_{i}$ of $1157 \pm 275 \mu \mathrm{M}$ for inhibiting uptake by EAAT2. Thus, the rank order of potency for EAAT2 was (from the lowest $\left.K_{i}\right)$ PDC $<\mathrm{T} \beta \mathrm{HA}<\mathrm{DHK}<\mathrm{KA} \ll \mathrm{SOS}$, whereas the rank order of potency for EAAT1 and EAAT3 was T $\beta$ HA $<$ PDC $<$ SOS $\ll$ DHK, KA (Fig. 4, Table 1). One drug moderately useful for discriminating between EAAT 1 and EAAT3 was $\mathrm{LA} \beta \mathrm{H}$, with $K_{i}$ values of $369 \pm 70 \mu \mathrm{M}$ and $133 \pm 34 \mu \mathrm{M}$, respectivcly.

\section{Electrogenic transport of glutamate and analogs in Xenopus oocytes}

Superfusion of voltage-clamped oocytes expressing the human EAAT subtypes with L-glutamate and other substrates resulted in inward currents that were dose dependent, saturable, and required the presence of sodium in the superfusion media (Fig. $5 A$ ). Kinetic parameters were determined by measuring the concentration dependence of the uptake currents (Fig. $5 B$ ). The transport mediated by each EAAT subtype was characterized for each glutamate and aspartate stereoisomer, and for several uptake inhibitors (Table 2). Transport was stereospecific for L-glutamate but not for D- or L-aspartate, a characteristic of these sodium-dependent uptake systems (Kanner and Schuldiner, 1987). The $K_{m}$ values obtained in this assay system were similar to those determined by measuring the uptake of ${ }^{3} \mathrm{H}-\mathrm{L}-$ glutamate and ${ }^{3} \mathrm{H}-\mathrm{D}$-aspartate in COS-7 cells expressing EAAT subtypes (compare Table 2, Fig. 3), although the affinity constants determined in oocytes were, in general, significantly lower than those measured in mammalian cells. The maximum current $\left(I_{\max }\right)$ associated with the uptake of substrates was also compared by normalizing $I_{\max }$ values to the maximum current obtained with L-glutamate in the same oocyte. These $I_{\max }$ values varied for each substrate, and the $I_{\max }$ values for a particular substrate varied between subtypes. Subtype-specific variations in $I_{\max }$ values were most dramatic for D-glutamate (Table 2). 
Glutamate uptake inhibitors such as PDC (Fig. 5A) and T $\beta$ HA also elicited transport currents, and the $K_{m}$ values determined by electrophysiology were comparable to the $K_{i}$ values determined by uptake competition in COS-7 cells (compare Tables $1,2)$.

\section{Mechanism of inhibition of EAAT2 uptake by KA and DHK}

Most inhibitors of glutamate uptake were found to evoke inward currents. In contrast, superfusion with KA did not evoke currents in voltage-clamped oocytes expressing any of the EAAT subtypes, suggesting that this compound is not a transport substrate (Fig. 6A). Moreover, the coadministration of KA did not affect the uptake currents elicited by L-glutamate in oocytes expressing either EAAT1 or EAAT3, in agreement with the lack of KA effect on ${ }^{3} \mathrm{H}$-glutamate uptake in transfected COS cells expressing these subtypes (Table 1). However, the EAAT2 glutamate-induced uptake current in oocytes was significantly reduced in the presence of KA (Fig. 6A). Similar results were obtained with the KA analogue DHK. To rule out the possibility that KA and DHK were transported by EAAT2 via a nunelectrogenic mechanism, radiolabeled $\mathrm{KA}$ uptake (at $1 \mu \mathrm{M}$ ) was compared to L-glutamate uptake (at $1 \mu \mathrm{M}$ ) in parallel assays of EAAT2-expressing and control COS-7 cells. Less than $0.1 \mathrm{pmol} /$ well $/ \mathrm{min}$ of $\mathrm{KA}$ uptake was measured, as compared with 44.3 $\mathrm{pmol} / \mathrm{well} / \mathrm{min}$ of specific L-glutamate uptake $(n=2)$. These data suggested that KA and DHK selectively block uptake mediated by the EAAT2 subtype without serving as substrates for uptake.

The mechanism of KA and DHK inhibition of EAAT2-mediated glutamate uptake was examined in greater detail by studying the effect of increasing concentrations of KA and DHK on the kinetic parameters for the L-glutamate uptake currents. Concentration-response curves to glutamate in the presence of 30 $\mu \mathrm{M}, 100 \mu \mathrm{M}$, or $300 \mu \mathrm{M} \mathrm{KA}$ were fitted to the Michaelis-Menten expression, and the glutamate concentration-response curves were shifted in a parallel manner (Fig. 6B). Similar data was obtained with DHK, suggesting that KA and DHK are competitive antagonists of EAAT2-mediated uptake. Schild analysis (Fig. 6C) provided estimates of the KA and DHK equilibrium dissociation constants as $16.7 \mu \mathrm{M}$ and $9.2 \mu \mathrm{M}$, respectively (Table 2).

\section{Discussion}

Three members of a gene family that mediate high-affinity sodium-dependent glutamatc uptake were identified by molecular cloning from human motor cortex. The isolation of the EAAT1, EAAT2, and EAAT3 cDNA sequences provides the means to express and characterize the properties of these transporters, which previously have been difficult to isolate functionally and study. The present study directly compares the sequence, distribution, and function of this human glutamate transporter gene family to identify similarities and differences reflecting the intrinsic properties of each subtype.

The regional distributions of EAAT1, EAAT2, and EAAT3 RNAs were compared in brain and in peripheral tissues by Northern blot analyses. Because of their postulated role in synaptic transmission, there is considerable interest in defining the particular cell types and neuronal pathways in which glutamate transporter subtypes are expressed. The rat transporters GLAST 1 (Storck et al., 1992) and GLT1 (Danbolt et al., 1992; Pines et al., 1992; Levy et al., 1993) were reported to be expressed by glia, while EAAC1 in brain was localized to neurons (Kanai and
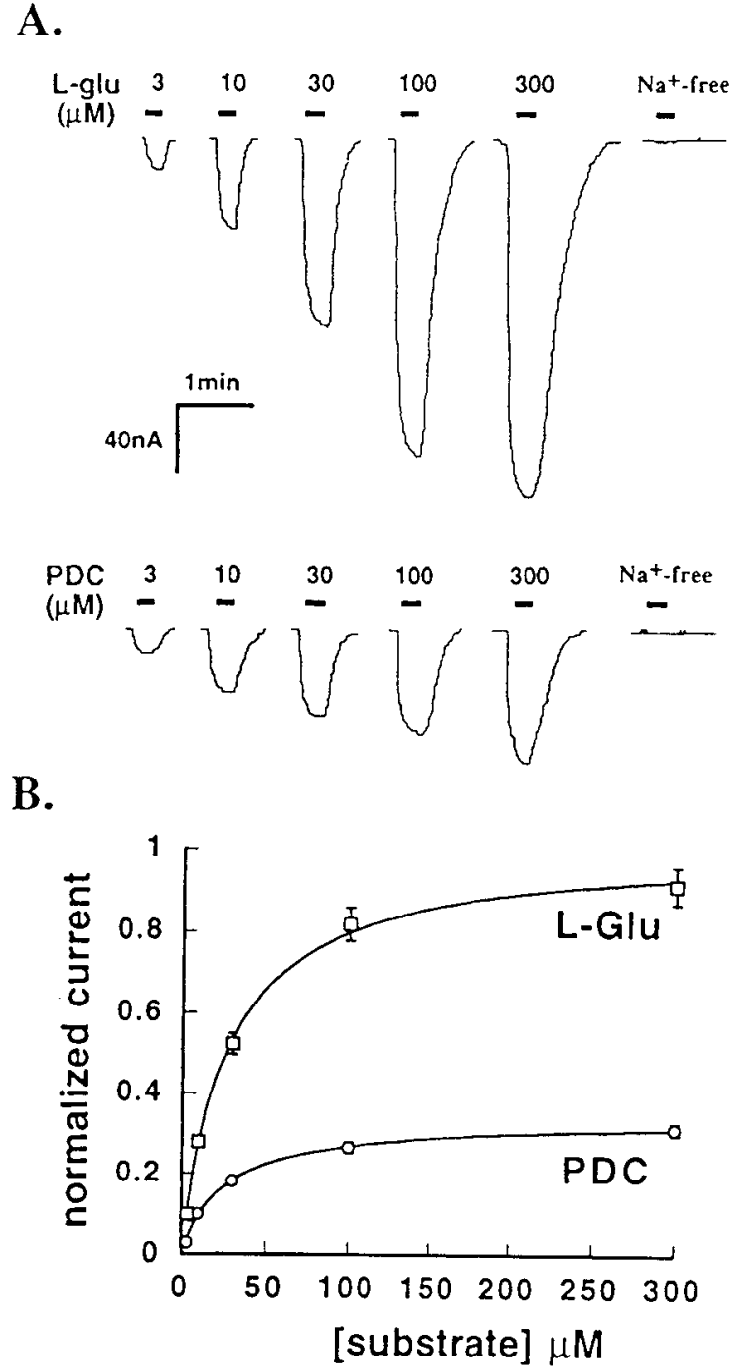

Figure 5. Electrogenic uptake in oocytes expressing EAAT subtypes. $A$, Inward currents were elicited by the application of substrates to oocytes injected with synthetic transporter RNAs and voltage clamped at $-60 \mathrm{mV}$. Dose-dependent and saturable responses to L-glutamate are shown for an oocyte expressing EAAT3. No uptake currents were observed when sodium was replaced with choline $\left(\mathrm{Na}^{+}-\right.$free). Superfusion of the same oocyte with PDC, a glutamate uptake inhibitor, evoked responses with properties similar to glutamate uptake currents. PDC, like most of the inhibitory compounds tested, is a glutamate transporter substrate. $B$, Uptake currents measured for L-glutamate and PDC were normalized to the maximum L-glutamate current determined in the same oocyte, and fitted to the Michaelis-Menten equation. The kinetic parameters listed in Table 2 for PDC and other substrates were obtained by this method.

Hediger, 1992). Sequence similarities initially suggested that EAAT 1 and GLAST1, EAAT2 and GLT1, and EAAT3 and EAAC 1 could be subtype counterparts in different species. Comparisons of our Northern distributions with those previously reported support the EAAT2/GLT1 correspondence and suggest that EAAT2 may be expressed in glia. However, differences in peripheral tissue distributions make the subtype correspondences of EAAT1/GLAST1 and EAAT3/EAAC1 less likely, and recent work in our laboratory that suggests the existence of additional subtypes makes the assignment of species homologs uncertain. Although our Northern blot analyses do not provide cellular resolution, they do provide insight into several aspects 
Table 2. Kinetic parameters of uptake in oocytes

\begin{tabular}{|c|c|c|c|c|c|c|}
\hline \multirow[b]{2}{*}{ Substrate } & \multicolumn{2}{|l|}{ EAAT 1} & \multicolumn{2}{|l|}{ EAAT2 } & \multicolumn{2}{|l|}{ EAAT3 } \\
\hline & $K_{m}(\mu \mathbf{M})$ & $I_{\max }{ }^{a}$ & $K_{m}(\mu \mathbf{M})$ & $I_{\max }{ }^{a}$ & $K_{m}(\mu \mathrm{M})$ & $I_{\max }{ }^{a}$ \\
\hline L-Glutamate & $20 \pm 3$ & (1) & $18 \pm 3$ & (1) & $28 \pm 6$ & (1) \\
\hline L-Aspartate & $16 \pm 1$ & $0.68 \pm 0.01$ & $7 \pm 1$ & $0.89 \pm 0.04$ & $24 \pm 2$ & $0.95 \pm 0.03$ \\
\hline D-Glutamate & $595 \pm 50$ & $1.10 \pm 0.06$ & $5360 \pm 420$ & $0.20 \pm 0.04$ & $1781 \pm 68$ & $0.66 \pm 0.04$ \\
\hline D-Aspartate & $23 \pm 2$ & $0.43 \pm 0.00$ & $13 \pm 1$ & $0.84 \pm 0.02$ & $47 \pm 8$ & $0.82 \pm 0.07$ \\
\hline $\mathrm{T} \beta \mathrm{HA}$ & $33 \pm 3$ & $0.55 \pm 0.01$ & $10 \pm 1$ & $0.33 \pm 0.02$ & $37 \pm 1$ & $0.94 \pm 0.01$ \\
\hline PDC & $28 \pm 2$ & $0.52 \pm 0.05$ & $7 \pm 0$ & $0.35 \pm 0.01$ & $27 \pm 5$ & $0.34 \pm 0.01$ \\
\hline $\mathrm{KA}$ & - & - & $16.7^{b}$ & $(0)$ & - & - \\
\hline DHK & - & - & $9.2^{b}$ & (0) & - & - \\
\hline
\end{tabular}

" $I_{\max }$ is normalized to the L-glutamate $I_{\max }$ in the same oocyte.

"Determined by Schild analysis; KA and DHK did not induce currents.

of EAAT mRNA expression. Expression of EAAT1 and EAAT3 is not restricted to the brain, suggesting a role in nutrient uptake in other tissucs. Moreover, the mRNA content of each EAAT subtype observed in different brain regions does not correlate well with the prevalence of glutamatergic neurons. Notably, EAAT subtypes were as abundant in the basal ganglia as in the hippocampus. Although the basal ganglia contains few glutamatergic neurons, extensive glutamatergic innervation may necessitate glial transporter functions. Alternatively, the participation of glutamate transporters in the metabolic uptake of acidic amino acids is observed in most tissues, and such functions may be attributed to EAAT subtypes in the brain. Assignment of functional roles in metabolism and/or synaptic function to individual subtypes awaits the determination of cell type specificity by histochemical analyses with cellular resolution.

EAAT1, EAAT2, and EAAT3 exhibit striking amino acid sequence similarities, and it could be that their structural diversity has been sharply constrained by the functional complexity of the uptake process. The translocation of glutamate across the cell membrane involves the binding and movement of substrate, but this process is also coupled to the cotransport of several $\mathrm{Na}^{+}$ions (Balcar and Johnston, 1972) and probably the countertransport of intracellular $\mathrm{K}^{+}$(Kanner and Sharon, 1978; Barbour et al., 1988) and $\mathrm{OH}^{-}$ions (Erecinska et al., 1983; Bouvier et al., 1992). The transmembrane topology of this family of membrane-bound glycoproteins is currently unresolved, with both 8 (Pines et al., 1992) and 10 (Kanai and Hediger, 1992) transmembrane regions models having been proposed previously. In comparing the sequences of the EAAT subtypes, we find that structural conservation is prevalent within, but not limited to, nine large hydrophobic regions (Fig. 1). Particularly well conserved are the sequences in the vicinity of the seventh and eighth hydrophobic region which includes both a serine-rich sequence motif and the conscrved AA(I/V)FIAQ structural motif utilized to isolate these gene products. The serine-rich sequence (SSSS in EAAT1 and EAAT3, ASSA in EAAT2) is similar to a sequence involved in glutamate binding to metabotropic glutamate receptors (O'Hara et al., 1993). If this motif should comprise a portion of the transporter glutamate binding site, these sequence differences could be related to the differential sensitivities of EAAT1/EAAT3 and EAAT2 to several uptake inhibitors (see below).

The molecular cloning of three glutamate transporter subtypes from a single species has enabled a direct comparison of their functional and pharmacological properties. Here, the functional properties of the human subtypes were compared in two different assay systems. Measurements of the radiolabeled L-glutamate uptake mediated by each EAAT subtype in transfected mammalian cells yielded $K_{m}$ values that varied between 48 and $97 \mu \mathrm{M}$. The ion flux that accompanies glutamate transport results in inward currents that were measured in voltage-clamped oocytes expressing each EAAT subtype. $K_{m}$ determinations by measurement of transport currents in oocytes were comparable to those determined by uptake in mammalian cells, although generally of higher affinity (18-28 $\mu \mathrm{M})$. System differences might be attributed to differences in lipid composition, posttranslational modifications, or other factors. Similar differences are found in the literature when uptake by synaptosomal or other membrane preparations are compared with whole cell uptake. Thus, differences between L-glutamate $K_{m}$ values previously reported for cloned glutamate transporter subtypes may in part be due to the different assays used. The reported $K_{m}$ for radiolabeled glutamate uptake by GLAST 1 expressed in oocytes was $77 \mu \mathrm{M}$ (Storck et al., 1992), whereas GLT1 was reported to have a $K_{m}$ of $10 \mu \mathrm{M}$ for uptake in intact mammalian cells and $2 \mu \mathrm{M}$ in membrane preparations (Pines et al., 1992), and EAAC1 yielded a glutamate $K_{m}$ of $12 \mu \mathrm{M}$ as determined by oocyte electrophysiology (Kanai and Hediger, 1992). Based on the higher reported $K_{m}$, it was suggested previously that GLAST1 might function as a low-affinity reserve uptake system (Kanai et al., 1993). The human glutamate transporters may have functional differences from those of other specics, but our measurements provided little evidence for significant subtype differences in affinity for L-glutamate.

A glutamate transporter pharmacology largely developed in rat synaptosomal preparation (Ferkany and Coyle, 1986; Fletcher and Johnston, 1991; Robinson et al., 1991, 1993) was applied to the cloned EAAT subtypes. Surprisingly, we found that $\alpha$-aminoadipate $(\alpha \mathrm{AA})$ exhibited very low potency in inhibiting glutamate uptake by the EAAT subtypes. This result contrasts with findings in rat cerebellar synaptosomes where an $\mathrm{IC}_{50}$ of 20-40 $\mu \mathrm{M}$ was determined for $\alpha \mathrm{AA}$ (Robinson et al., 1991, 1993), and with the previously reported sensitivity of cloned GLT1 and EAAC1 to this compound (Kanai and Hediger, 1992; Pines et al., 1992). ODAP, quisqualate and $\beta$-p-chlorophenylglutamic acid are other compounds reported to inhibit transport that were of low potency in our assays. ODAP was reported to potently inhibit transport in rat and primate synaptosomes (Lakshmanan and Padmanaban, 1974b), and it is the excitotoxin implicated 
A.
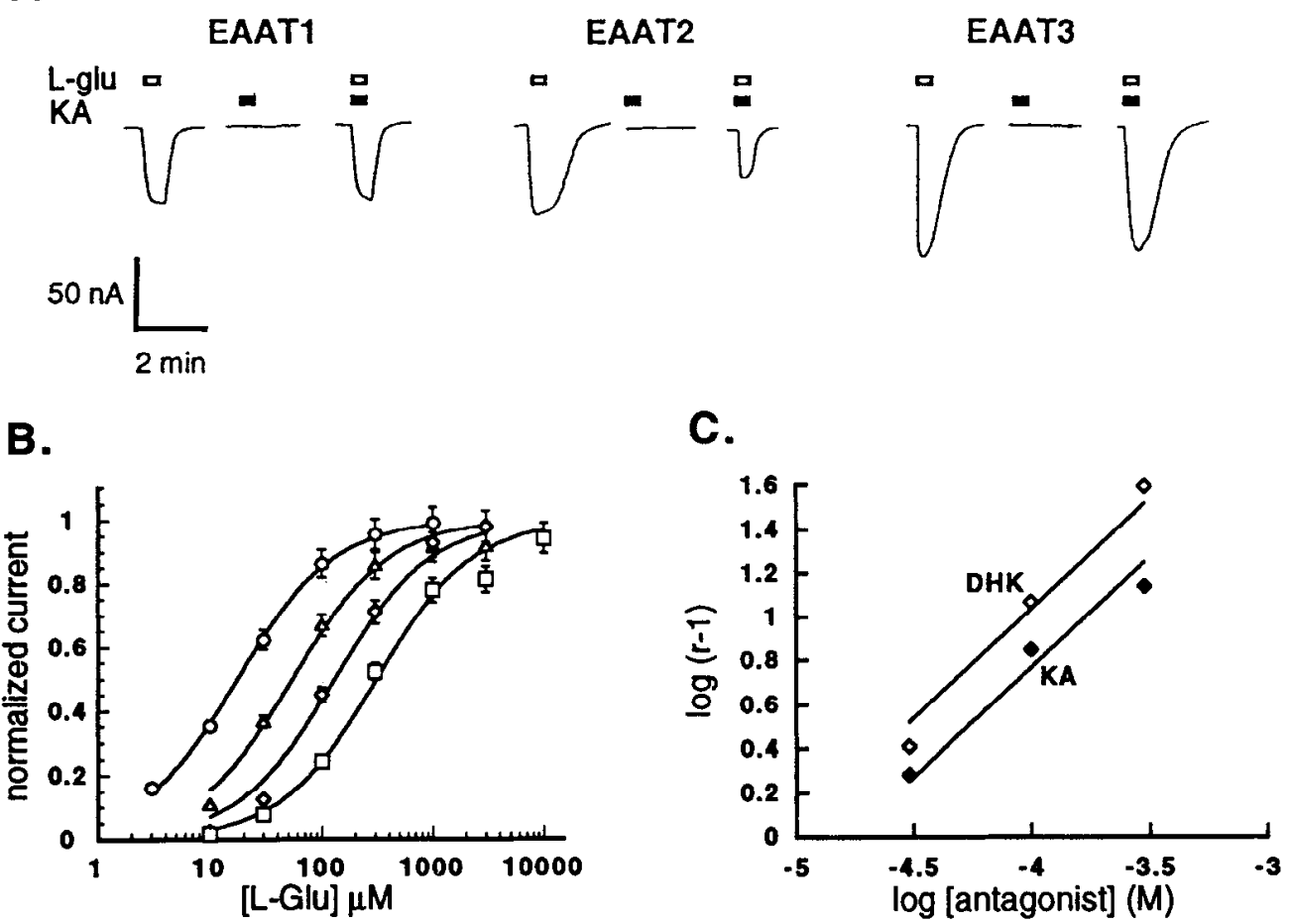

Figure 6. Kainate and dihydrokainate are competitive blockers of EAAT2-mediated uptake. $A$, The application of KA (100 $\mu \mathrm{M})$ did not elicit currents in oocytes expressing either EAAT1, EAAT2, or EAAT3. However, the currents elicited by L-glutamate $(100 \mu \mathrm{M})$ were inhibited significantly by the coadministration of KA in oocytes expressing EAAT2, but not EAAT1 or EAAT3. These data confirm that KA selectively blocks EAAT2mediated glutamate uptake. $B$, Dose-dependent inward currents elicited by the superfusion of EAAT2-expressing oocytes with L-glutamate (circles) undergo parallel shifts with the addition of $30 \mu \mathrm{M}$ (triangles), $100 \mu \mathrm{M}$ (diamonds), or $300 \mu \mathrm{M}$ (squares) of KA. Moreover, KA inhibition was abolished at high glutamate concentrations. These data indicate that KA competitively blocks EAAT2-mediated uptake. $C$, The antagonist equilibrium dissociation constants of KA (solid diamonds) and DHK (open diamonds) were estimated from Schild plots. The agonist dose ratio ( $r$ ) at each antagonist concentration was calculated from the data shown in $B$ for KA, and from similar DHK data not shown. Each line was fit to the data by least squares and with a slope of 1 , and the KA and DHK $K_{l}$ values given in Table 2 were obtained from the abscissal intercept.

in the human degenerative disease lathyrism (Spencer et al., 1986). These results may suggest pharmacological differences between the human subtypes and those of other species, but also indicate that other EAAT subtypes or glutamate transport systems exist. Regional differences in pharmacology have suggested the existence of at least four glutamate transporter subtypes (Robinson et al., 1993), and distinct glutamate uptake systems have also been described.

The EAAT subtypes fall into two distinct groupings based on differences in uptake inhibitor pharmacology. EAAT2-mediated uptake in mammalian cells was 7-10-fold more sensitive to PDC than the EAAT1 and EAAT3 subtypes (Table 1). The EAAT1/EAAT3 subtypes, on the other hand, were much more potently inhibited by SOS than was EAAT2. Pharmacological distinctions between the EAAT2 and EAAT1/EAAT3 subtypes, however, were most clearly demonstrated by KA and DHK. EAAT2-mediated transport in COS-7 cells was inhibited by KA and DHK with $K_{i}$ values of 23 and $59 \mu \mathrm{M}$, respectively, but these agents did not significantly affect uptake by EAAT1 or EAAT3. Compounds such as PDC were determined to be substrates because they elicited specific uptake currents in oocytes expressing the EAAT subtypes. KA and DHK, on the other hand, did not evoke currents via any EAAT subtype, and these compounds were found to inhibit only the glutamate uptake currents mediated by EAAT2. It has been reported previously that KA and DHK are not transport substrates (Lakshmanan and Padmanaban, 1974a; Johnston et al., 1979), and that both compounds, but particularly DHK, inhibit glutamate uptake with the greatest potency in synaptosomes prepared from rat striatum (Robinson et al., 1991, 1993). EAAT2 mRNA was the most abundant subtype transcript in human basal ganglia, and we identify this as a KA/DHK-sensitive subtype.

The structure of the glutamate conformer that binds to sodium-dependent glutamate transporters has been studied using structurally constrained glutamate analogs (Chamberlin and Bridges, 1993; Bridges et al., 1993). These studies utilized synaptosomal preparations likely to contain mixed subtypes, and the application of these structural concepts to the pharmacology of the cloned transporter subtypes is of interest. PDC, KA, and DHK are glutamate analogs that can be viewed as containing a similar embedded glutamate conformer, but differing by the addition of isopropenyl or isopropyl groups at the 4-positions of KA or DHK, respectively (Bridges et al., 1993; Chamberlin and Bridges, 1993). We found PDC to be a substrate of each EAAT subtype. KA/DHK did not interact with EAAT1 and EAAT3, possibly because of steric inhibition by the additional alkyl groups. The binding of KA/DHK to EAAT2, on the other hand, occurs with high affinity (equilibrium constants of 17 and $9 \mu \mathrm{M}$, respectively, in oocytes), but these agents cannot undergo membrane translocation. Structural differences between the EAAT2 and EAAT1/EAAT3 substrate binding sites should be identifiable that give rise to these distinct pharmacologies. None 
of the compounds that we have tested thus far provide such a clear distinction between the properties of EAAT1 and EAAT3, and this is an additional area for further investigations.

In addition to the activation of glutamate receptors, the interactions of excitatory amino acids and their analogs with highaffinity uptake systems can be a significant determinant of their neurotoxicity (Choi et al., 1987; Rosenberg et al., 1992). The toxicity of T $\beta$ HA, a high-affinity substrate for each EAAT subtype, may be due in part to the inhibition of glutamate uptake (McBean and Roberts, 1985). KA is one of the most potent neurotoxins known, and its toxicity relative to glutamate is likely to be enhanced because it is not readily taken up (Garthwaite, 1985). The weak inhibition of glutamate uptake described in rat brain synaptosomes by KA (Lakshmanan and Padmanaban, 1974a; Robinson et al., 1993) and the potent inhibition of the EAAT2 subtype demonstrated here may be additional component in KA toxicity. Lesion studies in the rat striatum have shown glutamatergic innervation to be essential for KA toxicity (McGeer et al., 1978), and elevated glutamate levels due to KA inhibition of uptake could provide an essential component of neurotoxicity. These data suggest the importance of understanding the interactions of excitatory amino acids and their analogues with the various transport systems. The cloning and functional assays utilized here to characterize EAAT1, EAAT2, and EAAT3 provide a basis for future research into the structure, function, and pharmacology of these transporters.

\section{References}

Amara SG, Arriza JL (1993) Neurotransmitter transporters: three distinct gene families. Curr Opin Neurobiol 3:337-344.

Andersson S, Davis DL, Dahlback H, Jornvall H, Russel DW (1989) Cloning, structure, and expression of the mitochondrial cytochrome P-450 sterol 26-hydroxylase, a bile biosynthetic enzyme. J Biol Chem 264:8222-8229.

Arriza JL, Kavanaugh MP, Fairman WA, Wu Y-N, Murdoch GH, North RA, Amara SG (1993) Cloning and expression of a human neutral amino acid transporter with structural similarity to the glutamate transporter gene family. J Biol Chem 268:15329-15332.

Arunlakshana O, Schild HO (1959) Some qualitative uses of drug antagonists. Br.J Pharmacol 14:48-58.

Balcar VJ, Johnston GAR (1972) The structural specificity of the high affinity uptake of L-glutamate and L-aspartate by rat brain slices. J Neurochem 19:2657-2666.

Barbour B, Brew H, Attwell D (1988) Electrogenic glutamate uptake in glial cells is activated by intracellular potassium. Nature 335:433435.

Barbour B, Brew H, Attwell D (1991) Electrogenic uptake of glutamate and aspartate into glial cells isolated from the salamander (Ambystoma) retina. J Physiol (Lond) 436:169-193.

Bouvier M, Szatkowski M, Amato A, Attwell D (1992) The glial cell glutamate uptake carrier countertransports $\mathrm{pH}$-changing anions. $\mathrm{Na}$ ture 360:471-474.

Bridges RJ, Lovering FE, Humphrey JM, Stanley MS, Blakely TN, Cristofaro MF, Chamberlin AR (1993) Conformationally restricted inhibitors of the high affinity L-glutamate transporter. Bioorg Med Chem Lett 3:115-121.

Bruns D, Engert F, Lux H-D (1993) A fast activating presynaptic reuptake current during serotonergic transmission in identified neurons of Hirudo. Neuron 10:559-572.

Chamberlin R, Bridges R (1993) Conformationally constrained acidic amino acids as probes of glutamate receptors and transporters. In: Drug design for neuroscience (Kozikowski AP, ed), pp 231-260. New York: Raven.

Cheng Y-C, Prusoff WH (1973) Relationship between the inhibition constant $\left(K_{\mathrm{i}}\right)$ and the concentration of inhibitor which causes 50 percent inhibition $\left(I_{\mathrm{so}}\right)$ of an enzymatic reaction. Biochem Pharmacol 22:3099-3108.

Choi DW, Maulucci-Gedde M, Kriefstein AR (1987) Glutamate Neurotoxicity in cortical cell culture. J Neurosci 7:357-368.
Chomczynski P, Sacchi N (1987) Single-step method of RNA isolation by acid guanidinium thiocyanate-phenol-chloroform extraction. Anal Biochem 162:156-159.

Christensen HN (1990) Role of amino acid transport and countertransport in nutrition and metabolism. Physiol Rev 70:43-77.

Danbolt NC, Storm-Matheisen J, Kanner BI (1992) An $\left[\mathrm{Na}^{+}+\mathrm{K}^{+}\right]$ coupled L-glutamate transporter purified from rat brain is located in glial cell processes. Neuroscience 51:295-310.

Eliasof S, Werblin F (1993) Characterization of the glutamate transporter in retinal cones of the tiger salamander. J Neurosci 13:402411.

Engelman DM, Steitz TA, Goldman A (1986) Identifying nonpolar transbilayer helices in amino acid sequences of membrane proteins. Annu Rev Biophys Chem 15:321-353.

Erecinska M, Wantorsky D, Wilson DF (1983) Aspartate transport in synaptosomes from rat brain. J Biol Chem 258:9069-9077.

Ferkany J, Coyle JT (1986) Heterogeneity of sodium-dependent excitatory amino acid uptake mechanisms in rat brain. J Neurosci Res 16:491-503.

Fletcher EJ, Johnston GAR (1991) Regional heterogeneity of L-glutamate and L-aspartate high-affinity uptake systems in the rat CNS. J Neurochem 57:911-914.

Fletcher EJ, Mewett KN, Drew CA, Allan RD, Johnston GAR (1991) Inhibition of high affinity L-glutamic acid uptake in rat cortical synaptosomes by the conformationally restricted analogue of glutamic acid, cis-1-aminocyclobutane-1,3-dicarboxylic acid. Neurosci Lett 121: 133-135.

Garthwaite J (1985) Cellular uptake disguises action of L-glutamate on $N$-methyl-D-aspartate receptors. Br J Pharmacol 85:297-307.

Hestrin S, Sah P, Nicoll RA (1990) Mechanisms generating the time course of dual component excitatory synaptic currents recorded in hippocampal slices. Neuron 5:247-253.

Hille B (1992) G protein-coupled mechanisms and nervous signaling. Neuron 9:187-195.

Isaacson JS, Solis JM, Nicoll RA (1993) Local and diffuse synaptic actions of GABA in the hippocampus. Neuron 10:165-175.

Johnston GAR, Kennedy SME, Twitchin B (1979) Action of the neurotoxin kainic acid on high affinity uptake of L-glutamic acid in rat brain slices. J Neurochem 32:121-127.

Kanai Y, Hediger MA (1992) Primary structure and functional characterization of a high-affinity glutamate transporter. Nature 360:467471.

Kanai Y, Smith CP, Hediger MA (1993) The elusive transporters with a high affinity for glutamate. Trends Neurosci 16:365-370.

Kanner BI (1993) Glutamate transporters from brain: a novel neurotransmitter transporter family. FEBS Lett 325:95-99.

Kanner BI, Schuldiner S (1987) Mechanism of transport and storage of neurotransmitters. CRC Crit Rev Biochem 22:1-38.

Kanner BI, Sharon I (1978) Active transport of L-glutamate by membrane vesicles isolated from rat brain. Biochemistry 17:3949-3953.

Krieg PA, Melton DA (1984) Functional messenger RNAs are produced by SP6 in vitro transcription of cloned cDNAs. Nucleic Acids Res 12:7057-7070.

Lakshmanan J, Padmanaban G (1974a) Effect of some "strong" excitants of central neurones on the uptake of L-glutamate and L-aspartate by synaptosomes. Biochem Biophys Res Commun 58:690 698.

Lakshmanan J, Padmanaban G (1974b) Effect of $\beta$ - $N$-oxalyl-L- $\alpha, \beta$ diaminopropionic acid on glutamate uptake by synaptosomes. Nature 249:469-471.

Lanthorn TH, Hood WF, Watson GB, Compton RP, Rader RK, Gaoni $\mathrm{Y}$, Monahan JB (1990) Cis-2,4-methanoglutamate is a potent and selective $N$-methyl-D-aspartate receptor agonist. Eur J Pharmacol 182: 397-404.

Levy LM, Lehre KP, Rolstad B, Danbolt NC (1993) A monoclonal antibody raised against an $\left[\mathrm{Na}^{++} \mathrm{K}^{+}\right]$coupled $\mathrm{L}$-glutamate transporter purified from rat brain confirms glial cell localization. FEBS Lett 317 : 79-84.

Lopeta M, Cleveland D, Sollner-Webb B (1984) High level transient expression of a chloramphenicol acetyl transferase gene by DEAEdextran mediated DNA transfection coupled with a dimethyl sulfoxide or glycerol shock treatment. Nucleic Acids Res 12:5707-5717.

McBean GJ, Roberts PJ (1985) Neurotoxicity of L-glutamate and DLthreo-3-hydroxyaspartate in the rat striatum. J Neurochem 44:247254. 
The Journal of Neuroscience, September 1994, 14(9) 5569

McGee EG, McGeer PL, Singh K (1978) Kainate-induced degeneration of neostriatal neurons: dependency upon corticostriatal tract. Brain Res 139:381-383.

Nichols D, Attwell D (1990) The release and uptake of excitatory amino acids. Trends Pharmacol Sci 11:462-468.

O'Hara PJ, Sheppard PO, Thogersen H, Venezia D, Haldeman BA, McGrane V, Houamed KM, Thomsen C, Gilbert TL, Mulvihill ER (1993) The ligand-binding domain in metabotropic glutamate receptors is related to bacterial periplasmic binding proteins. Neuron 11:41-52.

Pines G, Danbolt NC, Bjoras M, Chang Y, Bendahan A, Eide L, Koepsell H, Storm-Mathisen J, Seeberg E, Kanner BI (1992) Cloning and expression of a rat brain L-glutamate transporter. Nature 360:464467.

Raven T, Jeserich G, Danbolt NC, Manner BI (1992) Comparative analysis of sodium-dependent L-glutamate transport of synaptosomal and astroglial membrane vesicles from mouse cortex. FEBS Lett 312: 15-20.

Robinson MB, Hunter-Ensor M, Sinor J (1991) Pharmacologically distinct sodium-dependent $\mathrm{L}-\left[{ }^{3} \mathrm{H}\right]$ glutamate transport processes in rat brain. Brain Res 544:196-202.

Robinson MB, Sinor JD, Dowd LA, Merwin JFJ (1993) Subtypes of sodium-dependent high-affinity $\mathrm{L}-\left[{ }^{3} \mathrm{H}\right]$ glutamate transport activity: pharmacologic specificity and regulation by sodium and potassium. J Neurochem 60:167-179.

Rosenberg PA, Amin S, Leitner M (1992) Glutamate uptake disguises neurotoxic potency of glutamate agonists in cerebral cortex in dissociated cell culture. J Neurosci 12:56-61.

Sarantis M, Ballerini L, Miller B, Silver RA, Edwards M, Attwell D (1993) Glutamate uptake from the synaptic cleft does not shape the decay of the non-NMDA component of the synaptic current. Neuron 11:541-549.

Schwartz E, Tachibana M (1990) Electrophysiology of glutamate and sodium co-transport in a glial cell of the salamander retina. J Physio (Lond) 426:43-80.

Spencer PS, Ludolph A, Dwivedi MP, Roy DN, Hugo J, Schaumburg HH (1986) Lathyrism: evidence for role of the neuroexcitatory amino acid BOAA. Lancet 2:1066-1067.

Stork T, Schulte S, Hoffman K, Stoffel W (1992) Structure, expression and functional analysis of a $\mathrm{Na}^{+}$-dependent glutamate/aspartate transporter from rat brain. Proc Natl Aced Sci USA 89:10955-10959.

Tanka K (1993) Expression cloning of a rat glutamate transporter. Neurosci Res 16:149-153. 